\title{
Retinoic acid perturbs the expression of $X$ Xox.lab genes and alters mesodermal determination in Xenopus laevis
}

\author{
Hazel L. Sive ${ }^{1,2}$ and Pei Feng Cheng \\ Department of Genetics, Fred Hutchinson Cancer Center, Seattle, Washington 98104 USA
}

\begin{abstract}
Retinoic acid (RA) treatment of Xenopus laevis embryos leads to anterior truncation of the body axis (Durston et al. 1989; Sive et al. 1990). These initial studies suggested that RA may play a role in the patterning of the primary body axis. At least one target of RA was shown previously to be dorsal ectoderm. In this report we extend this observation and also ask whether RA alters the determination and inducing capacity of mesodermal tissue. To facilitate this analysis we isolated the homeo-domain-containing genes Xhox.lab1 and Xhox.lab2. These genes were expressed in both ectoderm and mesoderm during the RA-sensitive period and were strongly induced by RA in both germ layers. In particular, anterior regions expressed low levels of Xhox.lab RNAs in untreated embryos but showed increased expression after RA application. We show further that although RA-treated embryos contained anterior-inducing mesoderm, the amount of this activity appeared to be lower than that of controls. Additionally, we document that RA suppressed lateral (muscle) and ventral (blood) mesoderm differentiation. The data indicate that RA alters mesodermal determination and causes axial perturbation both by depressing the ability of dorsal mesoderm to induce anterior structures and by altering the response of dorsal ectoderm to induction. These analyses suggest that Xhox.lab genes may be responsible, in part, for mediating the $R A$ effect.
\end{abstract}

[Key Words: Retinoic acid; Xhox.lab genes; Xenopus laevis]

Received April 11, 1991; revised version accepted May 28, 1991.

Formation of the amphibian body plan occurs through both sequential and parallel inductive events. Dorsoventral axis formation requires a cytoplasmic/cortical rotation that occurs soon after fertilization (see Gerhart et al. 1989). This somehow allows the differential induction of dorsal, lateral, and ventral mesoderm in a process(es) that begins during cleavage stages (for review, see Smith 1989). Anteroposterior (A/P) axis formation occurs primarily during gastrulation as the dorsal mesoderm acquires A/P polarity (Gerhart and Keller 1986; Gerhart et al. 1989) and is responsible for inducing the dorsal ectoderm to assume a variety of fates, including neural derivatives (brain, spinal cord, and sense organs) and nonneural tissues (cement gland, hatching gland, and fins) (for review, see Nieuwkoop et al. 1985; Sive et al. 1989).

Retinoic acid (RA) is able to alter profoundly primary axis formation in the frog Xenopus laevis (Durston et al. 1989; Sive et al. 1990). In a dose-dependent way, RA acts during gastrula and early neurula stages to truncate progressively the resulting $\mathrm{A} / \mathrm{P}$ axis, with anterior structures being most sensitive. Both anterior mesodermal (heart) and ectodermal (cement gland, eyes, and brain) lineages are affected. Anterior-specific gene expression is

\footnotetext{
'Corresponding author.

${ }^{2}$ Present address: Whitehead Institute, Nine Cambridge Center, Cambridge, Massachusetts 02142 USA.
}

suppressed, with the concomitant increase of at least one posterior-specific RNA (Sive et al. 1990; see also Cho and de Robertis 1990). This was an intriguing finding for three reasons. First, the data indicated the existence of an anterior "domain" that may correspond to the head rudiment. Second, akin to its apparent role in A/P patterning of the limb bud (for review, see Eichele 1989), RA or a closely related compound may normally play a role in determination of the primary body axis, perhaps being required for posterior patterning. Third, RA is a novel and useful tool to add to the battery of epigenetic reagents ( $\mathrm{LiCl}$ and UV irradiation are others) that have been essential for dissecting many steps during amphibian axis formation (see Kao and Elinson 1988; Berridge et al. 1989; Gerhart et al. 1989). To understand the possible normal role of RA in A/P patterning and to exploit it as a probe of epistatic steps in this process, it seemed essential to fully characterize the targets of the RA-mediated perturbation.

Previous work indicated that at least one direct target of RA in altering the axial pattern is the dorsal ectoderm (Sive et al. 1990). In particular, RA effected the same spectrum of changes in gene expression and tissue differentiation when applied to isolated dorsal ectoderm as was seen in whole RA-treated embryos. Although ectoderm was clearly a target of RA in vitro, no measure was obtained in whole animals of whether the RA effects 
were mediated exclusively via an ectodermal route or whether alteration of the dorsal mesoderm was also involved. RA clearly perturbed gastrulation, causing failure of the archenteron to expand and, at high concentrations, delaying blastopore closure; these findings suggest that the character of the mesoderm was altered by RA and that the rapidly involuting anterodorsal mesoderm may have been converted to more slowly involuting posterodorsal or ventral mesoderm (Sive et al. 1990).

We therefore asked whether RA altered the positional values of dorsal mesoderm by analysis of mesodermal gene expression and by functional assays of its ability to pattern ectoderm. With the homeo-domain genes, Xhox. lab1 and Xhox.lab2 as markers, our results show that RA alters the $\mathrm{A} / \mathrm{P}$ character of dorsal mesoderm and also appears to decrease the anterior-inducing capacity of this tissue. The phenotype caused by RA thus appears to be a composite of both ectodermal and mesodermal perturbation.

\section{Results}

Xhox.lab genes are members of the labial gene family

We reasoned that Xenopus homologs of the labial gene family would provide markers for early division of the embryonic axis and for the response to RA. This supposition was based on the expression patterns of labial members in mouse and chicken. In these organisms, $1 a$ bial homologs (Ghox.lab and Hox-1.6 or Hox-2.9) are expressed in both the ectoderm and mesoderm, in the posterior of the embryo, beginning during gastrulation (LaRosa and Gudas 1988; Sundin et al. 1990; Frohman et al. 1990). These expression patterns may correspond to what would be a posterior RA-resistant domain in Xenopus, with expression occurring during the period when embryos are sensitive to RA-mediated perturbation.

The Ghox.lab homeo domain was used to screen a Xenopus gastrula library at low stringency (see Materials and methods). Two different Xhox.lab genes were isolated with rather divergent nucleotide and conceptual protein sequences that showed significant identity only over the labial and homeo domains (see Fig. 1C), where they were $\sim 85 \%$ identical. It was not clear, therefore, whether these genes were representatives of a single gene that diverged after the time Xenopus underwent tetraploidization (Kobel and DuPasquier 1986) or whether they were more ancient relatives. Additionally, the Xhox.lab2 labial and homeo domains were closely related to those of $\operatorname{Hox}-1.6$, displaying $\sim 97 \%$ identity.
The sequence of partial cDNA clones is presented in Figure 1, A and B. As shown in Figure 1C, these genes fall into the labial gene family on the basis of sequence similarity both within the homeo domain and in the aminoabutting labial domain. Xhox.1ab1 and Xhox.1ab2 encode RNAs of $\sim 1.5$ and $2.0 \mathrm{~kb}$. Both genes were expressed during gastrulation, with detectable RNA present by stage 10 (early gastrula; Nieuwkoop and Faber 1956). However, expression of Xhox.lab1 peaked in early neurula (stages 14/15), whereas Xhox.lab2 RNA levels were maximal in tail bud and hatching stages, before declining to very low levels in swimming tadpoles (stage 48) (Fig. 2).

\section{$R A$ induces Xhox.lab expression in both ectoderm and mesoderm}

We then asked where the Xhox.Iab RNAs were localized and whether these genes were responsive to RA. Embryos were given a pulse of $1 \mu \mathrm{M}$ RA during blastula stages (see Materials and methods) and, later, were either harvested whole or dissected, as described below, and analyzed by Northern hybridization for Xhox.lab expression.

Figure 3A shows that RA strongly induced both genes in mid-gastrula (stage 11.5) (lanes 1 and 2). Xhox.lab1 was induced $\sim 4$-fold, and Xhox.1ab2, was induced $\sim 10$ fold in whole embryos. This induction was particularly apparent in isolated dorsal mesoderm or ectoderm (lanes 3-10), where expression of both genes was induced $>10$ fold by RA. In ectoderm, the induction was apparent in both the presumptive cement gland (an anterior secretory organ; see Sive et al. 1989) and in more posterior fractions that included the remainder of the head and the presumptive trunk and tail (see legend to Fig. 3; Sive et al. 1990). Similarly, in underlying mesoendoderm, Xhox.lab RNAs were induced both in anterior (pharyngeal endoderm and head mesoderm) and more posterior (notochord) fractions. Although the levels of these RNAs were very low in untreated dorsal mesoderm and ectoderm, these RNAs appeared to be localized in more posterior regions (Fig 3A, lanes 3,4,7,8).

An older set of embryos (neurula, stage 14) were also analyzed for Xhox.lab induction by RA. As shown in Figure 3B, Xhox.lab1 RNA levels were only 1.5- to 2-fold higher than their levels in control embryos (lanes 1 and 2), whereas Xhox.lab2 levels remained $\sim 5$-fold higher than uninduced levels. At this stage, Xhox.lab1 RNA was localized predominantly in dorsal regions while

Figure 1. Sequence of Xhox.lab genes. (A) Nucleotide and conceptual protein sequence of a partial Xhox.lab1 cDNA clone. The labial domain, the homeo domain, and a 3'-poly(A) addition consensus are underlined. We do not know whether the amino terminus of the protein shares sequence similarity with mouse and chicken genes (La Rosa and Gudas 1987; Sundin et al. 1990). (B) Nucleotide and conceptual protein sequence of a partial Xhox.lab2 cDNA clone. The labial domain, the homeo domain, and a 3 '-poly(A) addition consensus are underlined. $(C)$ Comparison of the labial domain and abutting homeo domains of Xenopus, chicken, mouse, and Drosophila (Mlodzik et al. 1988) labial family members, with the Antennapedia (Schneuwly et al. 1986) homeo domain (Antp) shown for contrast. Residues shared by four or more genes are shown in uppercase letters. labial-specific consensus residues are in bold type and are shaded. 


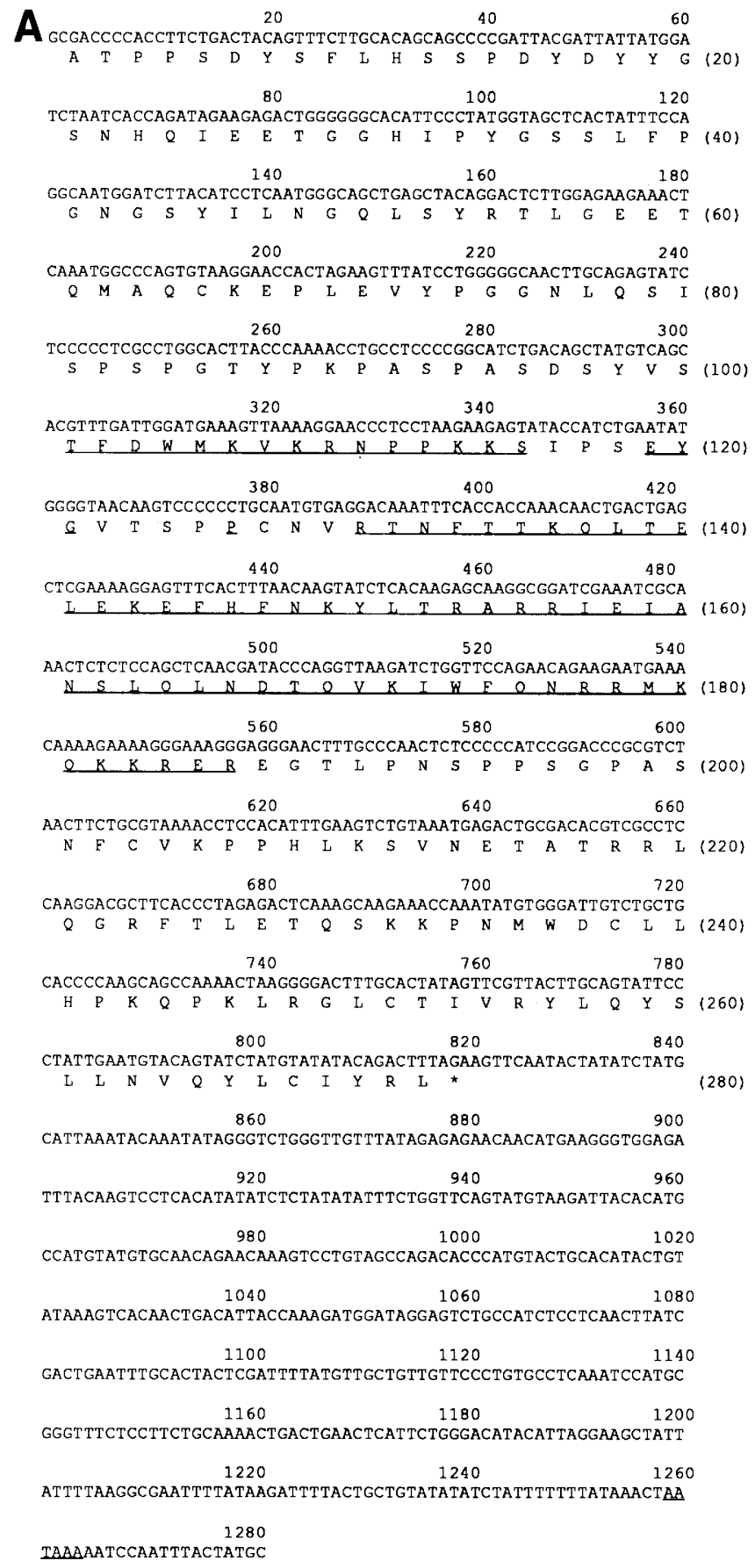

$820040 \quad 40$

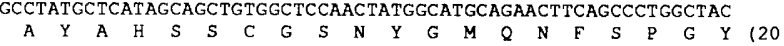
$\begin{array}{ccc}80 & 100 & 120 \\ \text { TCTCATTTCCCCATCCATCAAGAGACAGAGGTGAGCTCAGGC TTCCCCCAATCTGTCTAC }\end{array}$

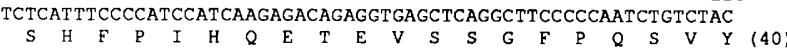
$\begin{array}{ccc}140 & 160 & 180 \\ \text { TCCGGCAACATCGCCTCGTCTGTGGTCCAGCACCAACAGCACCAGTCTTACATCGAGGGA } & \end{array}$

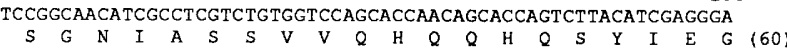
$200 \quad 220 \quad 240$ TCCGCTCACTATATCCACCATTCATACGGACCTGAGCAGACCTTTCTGTGGCTAATTAC
S A H $260 \quad 280 \quad 300$ AACAACAATGTAGCCAGCCTCCATATCAGCCAGAGGGAAGTTTGTCATTCCCCTTCCAGT $\begin{array}{lllllllllllllllllllll}N & N & N & V & A & S & L & H & I & S & Q & R & E & V & C & H & S & P & S & S & (100)\end{array}$

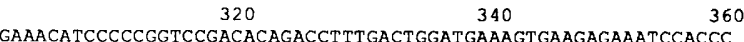

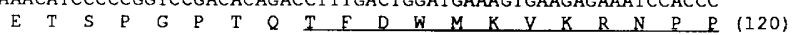
$380 \quad 400 \quad 420$ AAAACAGGTAAGGCCGGGGAATATGGTTATGCCGGCCAGCCCAACACAGCCAGGACCAAC K T G K A G E Y G Y A G E P N T A B T N (140) $440 \quad 460 \quad 480$

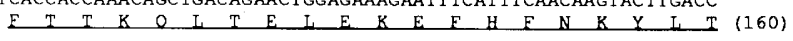
$\begin{array}{ccc}500 & 520 & 540\end{array}$ $B A R B \vee E I A$ A A L O I N E T O V K I (180) $560 \quad 580000$ TGGTTCCAGAACAGGAGGATGAAACAGAAAAAAAGGGAAAAAGAAGGACTTCTCCCCATC

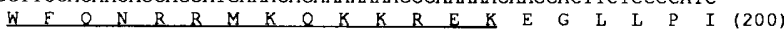
$620 \quad 640 \quad 660$ TCCCCATCAACCAGTACAGGAAGCGATGAAAAGTCAGAGGAGCTGTCAGAAAAGTCCAAT $\begin{array}{llllllllllllllllllllll}S & P & S & T & S & T & G & S & D & E & K & S & E & E & L & S & E & K & S & N & (220)\end{array}$ $680 \quad 700 \quad 720$

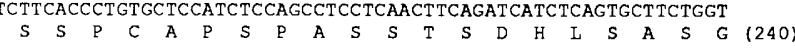

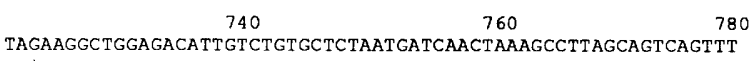
* $800 \quad 820 \quad 840$ AGTGATCTGCTGTATATGCCAGATtTCACCTGGTACCATCAAGgtTatattitatTtGCAC $\begin{array}{ccc}860 & 880 & 900 \\ \text { AAGTTTGGAAAGTCATTTTCGTTCTAAGCTACAATAACAAAATGAACTAAAAAATTTTT }\end{array}$ $\begin{array}{cc}920 & 940 \\ \text { GTGGCATGTGTCACCCCTATCTCTTGTTATGAGCTGCTAGGACAGGTCCACATGAGGGA }\end{array}$ $980 \quad 1000 \quad 1020$ CATTCCTGCTGGGAAACAACTGGT TGCAGATCCTCAAAGACTGATGCACTACTTAAAAAA $\begin{array}{rrr}1040 & 1060 & 1080\end{array}$ GCAAAGTT TACACAAGTTAATAGACGTTTATTTAATTTAAAGTTCGACGGTGTCTGTATG $\begin{array}{ccc}1100 & 1120 & 1140 \\ \text { TGAAAAGAGTGTACATATATTGTTCCAGAGATTTATCTTTGAGTGTTTTGTAGAATTCT }\end{array}$ $\begin{array}{ccc}1160 & 1180 & 1200 \\ \text { AAATAATTATGAGATGATGGAATGGTAAAAAAGCTCAATGTTTCTAGCACAGGAGAAC }\end{array}$ $\begin{array}{ccc}1220 & 1240 & 1260 \\ \text { AGCAGTGTTTGCTGACCGCATACCTCAGTAATCTCTCTCATTTACTAGGTGTTTACAGTC } & \end{array}$ $\begin{array}{ccc}1280 & 1300 & 1320 \\ \text { ATGATT TTAGGTGAATATCGTATACGTTTTTGTTTTTTGGTCAAGGTCCAATTTCCAGG } & \end{array}$ $\begin{array}{ccc}1340 & 1360 & 1380 \\ \text { GTATATTT TCCAAACAAAACCCAATTGTTCTCTGCTCCAAGAGAAACGCTTCTGATCGCC }\end{array}$ $\begin{array}{ccr}1400 & 1420 & 1440 \\ \text { TTTTATCTTGTAAGAGCAAAAACGTGTGTATAGTTGTGATTACATCGCGAACCCCCTT }\end{array}$ $\begin{array}{ccr}1460 & 1480 & 1500 \\ \text { TGCATGACGCCGAATGTAAACTGAGTTTTATCAGTTGGATTTGTCAATAAAATATTCT }\end{array}$ ATrTt
Xhox.labl Xhox. lab2 Ghox.1ab Hox 1.6 Hox 2.9 labial Antp

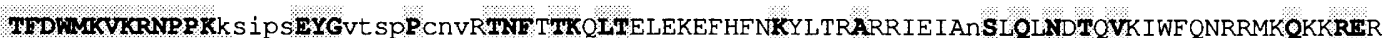

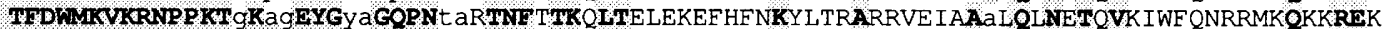

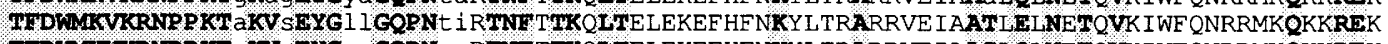

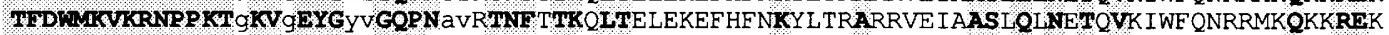

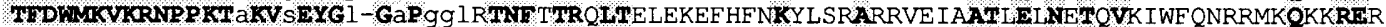
ahpngmgvglgsgsgls scslssnt nNsgRTNF TnKOLTELEKEF HF NRYL TRARR IE IAnTIQLNETOVK IWF QNRRMKQKKRVK

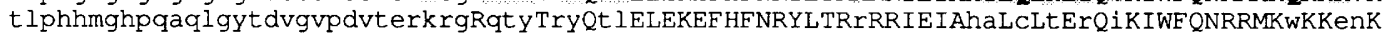

Figure 1. (See facing page for legend.) 


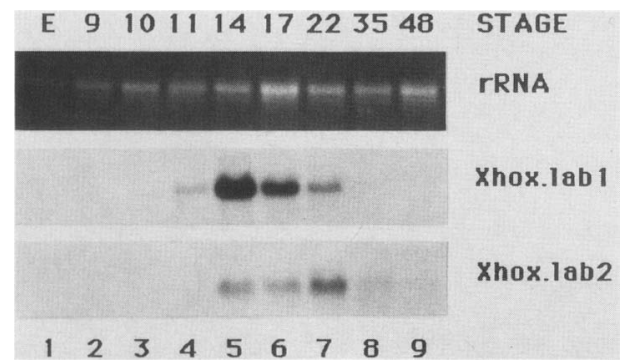

Figure 2. Developmental profile of Xhox.lab RNAs. Five micrograms of total RNA from embryos of the stages shown was analyzed by Northern hybridization (see Materials and methods) for Xhox.lab sequences. Embryos were staged according to Nieuwkoop and Faber (1956). An ethidium bromide-stained panel of 28S rRNA is shown for comparison of loadings. The exposure shown was made for 2 days. Upon longer exposure, Xhox.lab RNAs were clearly visible in stage-10 RNA. (Lane 1) Egg; (lane 2) stage 9 (blastula); (lane 3) stage 10 (early gastrula); (lane 4) stage 11 (mid-gastrula); (lane 5) stage 14 (early neurula); (lane 6) stage 17 (mid-neurula); (lane 7) stage 22 (tail bud); (lane 8) stage 35 (hatching); (lane 9) stage 48 (swimming tadpole).

Xhox.lab2 RNA was distributed equally between dorsal and ventral regions in locations that included both dorsal mesoderm and ectoderm (not shown). Significantly, the distribution of these RNAs was altered for both genes. Although in control embryos, Xhox.lab1 RNA was concentrated in middle and tail regions, $R A$ also induced the expression of this gene in the RA-sensitive head region (Fig 3B, lanes 3-8). Expression of these genes in more posterior regions declined slightly. Xhox.lab2 RNA was predominantly expressed in middle regions of control animals, but also became localized in head and tail regions in the presence of RA (lanes 3-8). In contrast, the distribution and levels of Xhox3 RNA, a gene involved in posterior patterning of the mesoderm (Ruiz i Altaba and Melton 1989a,b,c), was not altered by RA, indicating that RA treatment altered expression of only a subset of homeo-domain genes (see also Fig. 6, below). Similar results have been obtained independently by Ruiz i Altaba and Jessell (1991).

In summary, these data showed that Xhox.lab RNAs were strongly inducible by RA in regions of the embryo that were perturbed by RA during the RA-sensitive period that occurred during gastrula and early neurula stages. Transcripts were localized in both dorsal ectoderm and mesoderm and in more posterior regions, and their distribution spread to anterior regions following RA application.

Dorsal mesoderm (organizer) from RA-treated embryos has reduced capacity to induce head structures in transplantation assays

The induction and altered distribution of Xhox.lab RNAs after RA treatment indicated that the A/P patterning of the dorsal mesoderm had been perturbed and suggested that the inducing ability of this tissue also may have been altered. A set of experiments was therefore performed to address the ability of dorsal mesoderm isolated from RA-treated embryos to induce anterior-specific structures when transplanted into host embryos. This type of assay was originally employed by Spemann and Mangold (see Spemann 1938) and was used to define the existence of organizer tissue (dorsal mesoderm) in Urodele embryos (see also Ruiz i Altaba and Melton 1989a).

A region of endoderm and mesoderm, including and lying superior to the dorsal blastopore lip, was excised from early gastrula-stage embryos (stage 10.25; Nieuwkoop and Faber 1956). Explanted tissue was inserted immediately into the blastocoel of a host embryo of equivalent age (see Fig. 4A; Materials and methods). Donors either had been exposed to several hours of RA treatment or were untreated (see Materials and methods). The extent of RA treatment was sufficient to prevent formation in intact embryos of any anterior structures, including eyes, cement gland, and heart (Fig. 4B). To provide a neutral environment for assessing the inducing ability of dorsal mesoderm, host embryos were UV-irradiated. Such embryos lack endogenous axial organizer capacity (see Scharf and Gerhart 1983; Gerhart et al. 1989) and develop axially, as radially symmetric, ventralized animals (Fig. 4B). The transplantation assays therefore analyzed the ability of control or RA-treated dorsal mesoderm to restore axial structures to UV-irradiated embryos. Transplants were scored morphologically $\sim 3$ days later for the appearance of dorsal axial structures.

As shown in Figure 4B and Table 1, dorsal mesoderm from control embryos was able to restore axial patterning to UV-treated hosts and elicited the formation of both eyes and a cement gland. Conversely, although RAtreated organizer was capable of inducing, in a significant percentage of embryos, some anterior development, including a cement gland, this tissue never induced eyes. No difference in the percentage of embryos with induced tails was observed with normal or RA-treated mesodermal transplants.

These data allowed two conclusions. First, dorsal mesoderm from RA-treated animals contained some anterior-inducing ability but less than that of controls. This difference did not appear to be due to carryover of RA in the transplants and perturbation of the ectodermal response to induction (see below; Sive et al. 1990), because when host embryos were untreated (non-UV-irradiated), no difference between the inducing ability of normal and RA-treated organizers was seen. We suggest that the discrepancy of results in these two assays was caused by the interaction and rescue of RA-treated organizer by normal, but not UV-treated, host organizer, perhaps in a dorsalization interaction (Dale and Slack 1987; Stewart and Gerhart 1990). Ruiz i Altaba and Jessell (1991) and Cho et al. (1991) have reported a loss of anterior-inducing ability in RA-treated dorsal mesoderm transplanted into normal embryos. Although our conclusions are similar to those of the investigators above, we do not know why the details of our assays differ. Presumably, this reflects some aspect of experimental design. Second, our data 
A

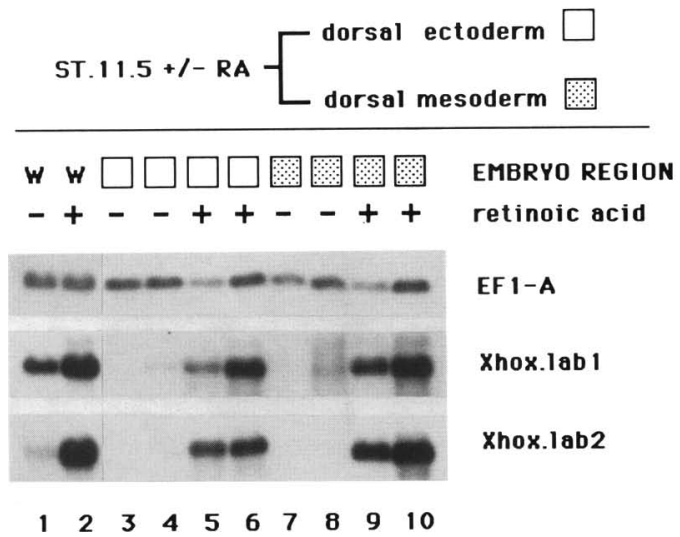

$\underline{\mathrm{B}}$

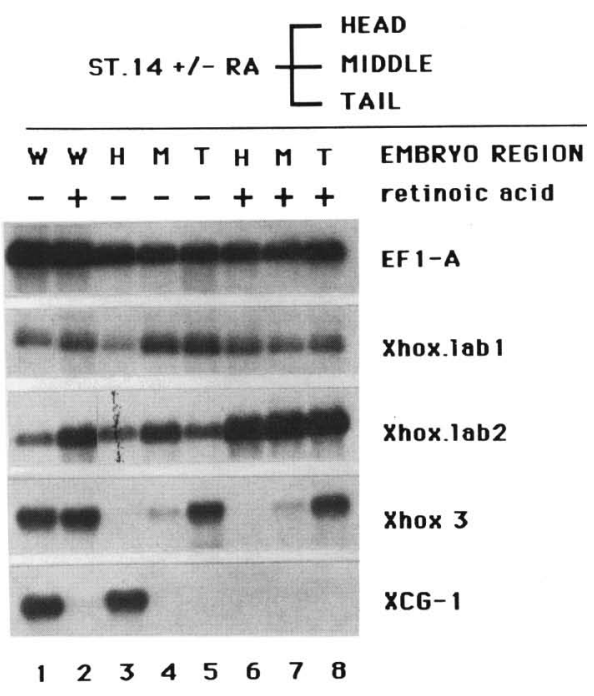

Figure 3. RA alters the expression of Xhox.lab RNAs. (A) Alteration of Xhox.lab RNA expression by RA. Blastula-stage embryos (stage 8; Nieuwkoop and Faber 1956) were treated with $1 \mu \mathrm{M}$ RA for $4 \mathrm{hr}$, until early gastrula (stage 10.25). Stage-11.5 (mid-gastrula) untreated or RA-treated animals were either harvested whole, or dorsal ectoderm or mesoderm was removed as described previously (Sive et al. 1989; see Materials and methods). Ectoderm and mesoderm were divided into anterior and posterior fragments. The anterior ectodermal fragments contained the presumptive cement gland, which had, at this stage, been induced but had not yet begun to differentiate (Sive et al. 1989). The more posterior ectodermal fragment contained the remainder of the head primordium and the presumptive trunk and tail (Keller 1976; Sive et al. 1990). The anterior mesodermal fragment contained future pharyngeal endoderm and head mesoderm, whereas the more posterior fragment contained mostly future notochord (Keller 1976). RNA expression was analyzed by Northern hybridization (see Materials and methods). One blot was stripped and reprobed with EF-l $\alpha$ (EF-1A) RNA for comparison of loadings (Krieg et al. 1989). Exposures shown were made for 10 days for Xhox.lab genes and $12 \mathrm{hr}$ for EF-1 $\alpha$. (Lane 1) Whole, untreated embryos; (lane 2) whole, RA-treated embryos; (lane 3) anterior dorsal ectoderm from control embryos; (lane 4) posterior dorsal ectoderm from control embryos; (lane 5) anterior dorsal ectoderm from RA-treated embryos; (lane 6) posterior dorsal ectoderm from RA-treated embryos; (lane 7) anterior dorsal mesoderm from control embryos; (lane 8) posterior dorsal mesoderm from control embryos; (lane 9) anterior dorsal mesoderm from RA-treated embryos; (lane 10) posterior dorsal mesoderm from RA-treated embryos. (B) Spatial distribution of Xhox.lab and Xhox3 RNAs. Embryos were given a pulse of RA as described in $A$ and harvested at early neurula, stage 14 (Nieuwkoop and Faber 1956), or dissected into head, middle, and tail thirds before harvest. Embryo-equivalents (3.5) of each RNA were analyzed by Northern hybridization. Xhox3 is a homeo-domain-containing gene involved in posterior patterning (see text and Ruiz i Altaba and Melton 1989a). XCG-1 is a cement-gland-specific gene (Sive et al. 1989) that is RA sensitive (Sive et al. 1990/. Blots were reprobed with EF-1 $\alpha$ RNA for comparison of loadings. Exposure times were 10 days for Xhox.lab genes and Xhox3, $24 \mathrm{hr}$ for XCG-1, and $12 \mathrm{hr}$ for EF-1 $\alpha$. (Lane 1) Whole, untreated embryos; (lane 2) whole embryos, treated with RA; (lane 3) head fragment from control embryos; (lane 4) middle fragment from control embryos; (lane 5) tail fragment from control embryos; (lane 6) head fragment from RA-treated embryos; (lane 7) middle fragment from RA-treated embryos; (lane 8) tail fragment from RA-treated embryos.

show that any anterior-inducing ability present in the RA-treated animals was somehow prevented from realizing its inductive capacity by a lesion that occurred independently of the formation of dorsal mesoderm.

\section{Ectoderm from RA-treated embryos is unable to respond normally to inducing mesoderm}

Previous studies have indicated that induced dorsal ectoderm is a direct target for RA (Durston et al. 1989; Sive et al. 1990). Our transplantation assays corroborated this theory by indicating that an alteration in the inducing ability of the dorsal mesoderm could not fully account for the RA phenotype. We therefore examined in greater detail the response of normal and RA-treated ectoderm to induction, employing in vitro conjugation assays.

Involuted dorsal mesoderm was isolated from control or RA-treated mid-gastrula embryos and conjugated with naive ectoderm from RA-treated or control early gastrula. After incubation in neutral saline, patterns of specific gene expression were analyzed by Northern hybridization. The genes assayed included the anterior-specific, RA-sensitive, ectodermal genes XCG-1, XAG-1, and XA-1 (Hemmati-Brivanlou et al. 1990; Sive et al. 1990). All of these genes are expressed in the cement gland; $\mathrm{XA}-1$ is expressed further, more posteriorly, in the hatching gland.

Figure 5 shows the results of such an assay. Dorsal mesoderm from both control and RA-treated mid-gastrula (stage 11.5) was equally capable of inducing, in control, early gastrula (stage 10) ectoderm, XCG-1, XAG-1, and XA-1 (lanes 3 and 4). In contrast, neither control nor RA-treated mesoderm induced XCG-1 or XAG-1 when conjugated with ectoderm from RA-treated embryos 


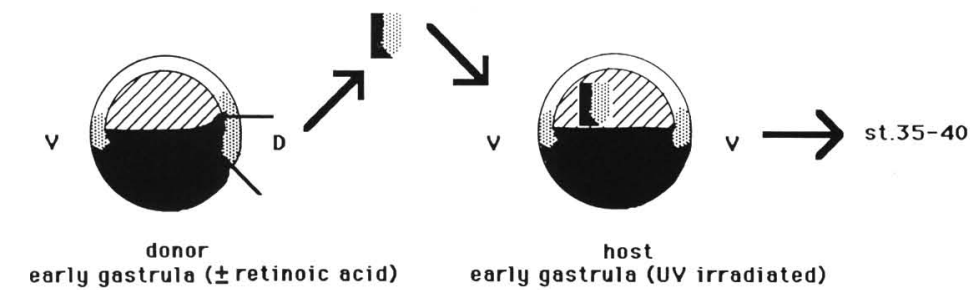

Figure 4. Effects of control or RA-treated organizer transplantation. (A) Scheme of transplantation. Donor embryos at stage 10.25 (early gastrula) were either untreated or had been incubated for $4 \mathrm{hr}$ in $1 \mu \mathrm{M}$ RA prior to operation (from mid-blastula to early gastrula). Host embryos had been UVirradiated soon after fertilization (see Materials and methods). Before any manipulations were performed, RA-treated donors and hosts were washed extensively in the absence of RA. A region of tissue including the dorsal lip of the blastopore and extending $\sim 30^{\circ}$ superior was removed from donor embryos. Both superficial and underlying tissue was taken. This tissue comprised endoderm (solid black area) and mesoderm (stippled area), but no ectoderm (open area), as judged by the absence of ectoderm-specific marker gene expression in tissue that was allowed to differentiate in vitro for $\sim 24$ $\mathrm{hr}$ after explantation (not shown). Immediately after removal from a donor, the tissue was inserted into the blastocoel (hatched area) of a host embryo. Hosts were allowed to develop for 2-3 days until hatching or swimming stages and were then examined morphologically for the presence of eyes or cement gland (see also Table 1; Materials and methods). (D) Dorsal; (V) ventral. (B) Examples of organizer transplants into UVirradiated hosts. (Top) RA-treated (upper embryo) and UV-irradiated (lower embryo) siblings of embryos used as donors and hosts, respectively, at stage 35 . (Bottom left) Axial rescue by normal organizers transplanted into UV-irradiated hosts. (Bottom right) Axial rescue by RA-treated organizers transplanted into UV-irradiated hosts. (Open arrows) Eyes; (white arrows) cement glands. Note the range of axial rescue in both cases (see also Table 1).
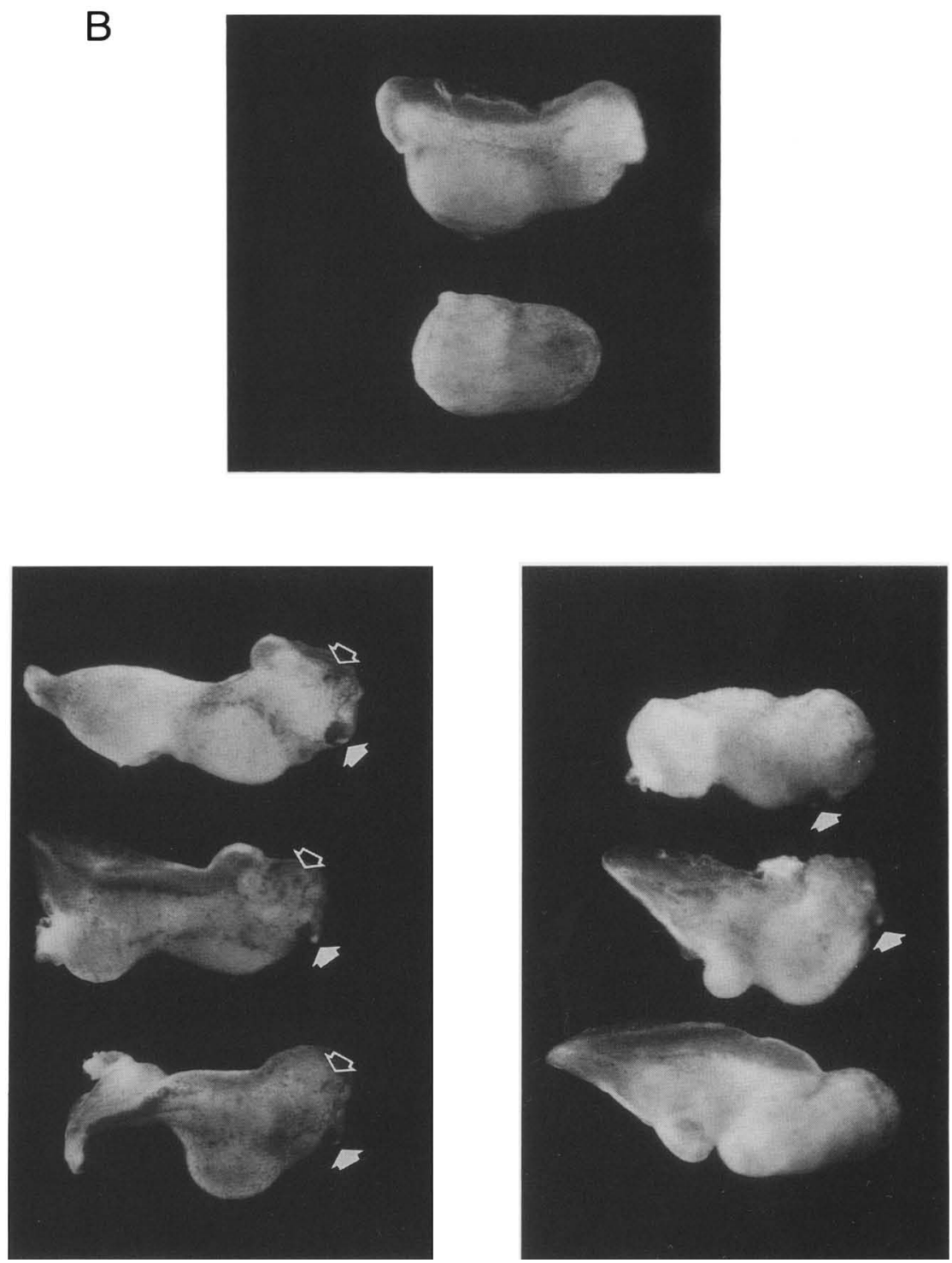

(lanes 5 and 6). Interestingly, however, XA-1 was induced to similar levels in both cases (lanes 5 and 6). The neural marker XIF3 (Sharpe et al. 1989) was expressed in all conjugates. As a control for reversal of RA effects following explantation and culture, explants of mid-gastrula ectoderm (i.e., that had already been induced in vivo), with or without underlying mesoderm, were removed from the RA-treated and control animals at the time of mesoderm isolation and incubated in neutral saline, in parallel with the conjugates. Although control explants went on to express high levels of all genes tested, explants from RA-treated animals failed to express any of 
Table 1. Transplantation of organizer (dorsal mesoderm) from $R A$-treated and normal donor gastrulae into $U V$-irradiated host embryos: analysis of axial rescue

\begin{tabular}{|c|c|c|c|c|c|}
\hline \multirow[b]{2}{*}{ Experiment } & \multirow[b]{2}{*}{$\begin{array}{l}\text { Donor }^{\mathrm{a}} \\
(\mathrm{DAI})^{\mathrm{c}}\end{array}$} & \multirow[b]{2}{*}{$\begin{array}{l}\text { Host }^{b} \\
{\text { (DAI })^{\mathrm{c}}}^{\text {(D) }}\end{array}$} & \multicolumn{3}{|c|}{$\begin{array}{l}\text { Percent with induced } \\
\text { axial structures } \\
\text { (no. assayed })^{\mathrm{d}}\end{array}$} \\
\hline & & & eyes & $\begin{array}{l}\text { cement } \\
\text { gland }\end{array}$ & tail \\
\hline \multirow[t]{3}{*}{1} & control (5) & UV $(0)$ & 50 & 100 & $45(20)$ \\
\hline & RA-treated & & & & \\
\hline & $(1-2)$ & Oviv & 5 & 75 & $60(20)$ \\
\hline \multirow[t]{2}{*}{2} & $\begin{array}{l}\text { control }(5) \\
\text { RA-treated }^{\mathrm{e}}\end{array}$ & UV $(0-1)$ & 59 & 71 & $88(17)$ \\
\hline & $(1-2)$ & UV $(0-1)$ & 0 & 20 & $85(20)$ \\
\hline
\end{tabular}

${ }^{a} \mathrm{~A}$ region including and extending $\sim 30^{\circ}$ above the dorsal blastopore lip (to include both uninvaginated and all invaginated tissue) was excised from early gastrula embryos (stage 10.25; Nieuwkoop and Faber 1956) and employed as donor tissue (see Materials and methods). Sibling embryos were allowed to develop to hatching stages and were then scored for DAI value (see below).

${ }^{b}$ Fertilized eggs were irradiated with $260-\mathrm{nm}$ UV light between 0.2 and 0.6 of the interval between fertilization and first cleavage (which occurs $\sim 90 \mathrm{~min}$ after fertilization), according to Scharf and Gerhart (1983) (see also Materials and methods). At the time when control embryos had reached stage 10.5 (early gastrula|, UV-treated animals that displayed no sign of blastopore formation were employed as hosts. Donor tissue was inserted into a slit made in the apical region of the animal hemisphere.

'Dorsoanterior index (DAI) was scored as detailed previously (Scharf and Gerhart 1983; Kao and Elinson 1988), with modifications described in Sive et al. (1990). (5.0) Normal; (4.0) reduced forehead, slightly cyclopic; (3.0) extremely cyclopic, normal or reduced cement gland; (2.5) no eye pigment, some cement gland; (2.0) no cement gland, beating heart, and otic vesicle present; (1.0) no beating heart, no otic vesicle, somites, and neural tube present; $(0)$ no axial structures.

${ }^{\mathrm{d}}$ Anterior structures scored were eye(s) and cement gland. The presence of a heart could not be scored easily. Additionally, melanophore formation was observed only in control transplants (not shown).

${ }^{e}$ Embryos were extensively dejellied and bathed in $1 \mu \mathrm{M}$ retinoic acid in $0.1 \times$ MBS from stage 7 to 10.25 ( 4 hr) (see Materials and methods). Embryos were washed, and their vitelline membranes were removed before dissection. Embryos allowed to develop in parallel to score DAI value were devitellinized at the same time as donors, to remove any traces of RA adhering to the vitelline membrane.

the three anterior-specific genes tested (lanes 7-10). Similarly, whole RA-treated sibling embryos failed to express this spectrum of markers (not shown).

It was not clear why XA-1 could be induced in RAtreated ectoderm when other anterior-specific, RA-sensitive genes (XCG-1 and XAG-1) could not. Possibly, while RA could alter the ectoderm to prevent initial induction of XCG-1 and XAG-1, expression of XA-1 could be prevented only after its initial induction had occurred. Although RA is not easily washed out of embryos, the
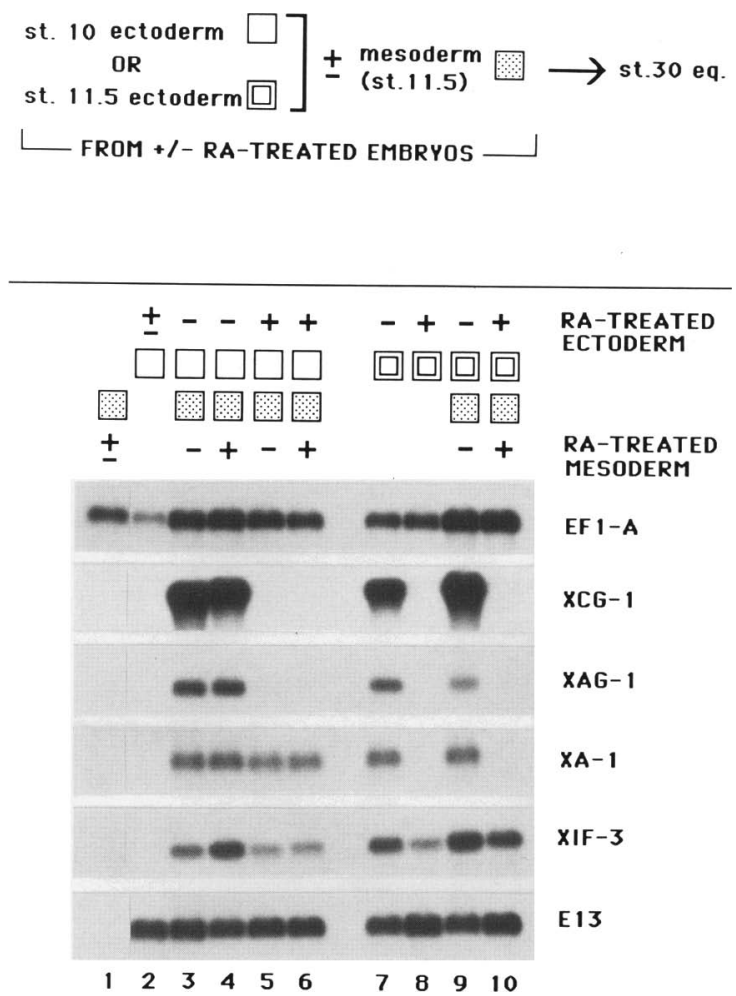

Figure 5. In vitro induction assays. Ectoderm was isolated from control or RA-treated early gastrulae (stage 10) and either cultured alone in neutral saline or conjugated with dorsal mesoderm isolated from control or RA-treated mid-gastrulae (stage 11.5). Additionally, dorsal ectoderm alone or with its underlying mesoderm was removed from control or RA-treated midgastrulae and cultured in neutral saline. All explants were incubated until control animals reached stage 30 (prehatching). Note that no RA was added during the culture period. Nucleic acid was prepared and analyzed for specific RNAs, as described in Materials and methods. Each lane represents a pool of 10-15 explants. Probes used are as follows: The translation elongation factor EF-1 $\alpha$ (Krieg et al. 1989) is used to normalize loadings per lane; XCG-1, XAG-1, and XA-1 are anterior-specific, RA-sensitive ectodermal markers; XCG-1 and XAG-1 are essentially cement gland-specific; XA-1 is predominantly expressed in the area of the hatching gland (Sive et al. 1989; Hemmati-Brivanlou et al. 1990); XIF3 is a neural marker, corresponding to a peripherin gene and expressed predominantly in anterior cranial nerves and motor neurons (Sharpe et al. 1989); E13 is an epidermal cytokeratin probe (J. Roberts, unpubl.), a marker of uninduced ectoderm. Exposure times: (XIF-3) 10 days; (XCG-1, XAG-1, and XA-1) 2 days; (EF-1A and E13) $\sim 12$ hr. (Lane 1) Stage- 11.5 mesoderm, incubated until stage 30 equivalent; (lane 2) stage-10 ectoderm, an equal mixture from control and RAtreated donors; (lane 3) stage-10 ectoderm from control embryos conjugated with stage-11.5 mesoderm from control embryos; (lane 4) stage-10 ectoderm from control embryos conjugated with mesoderm from RA-treated donors; (lane 5) stage-10 ectoderm from RA-treated embryos conjugated with mesoderm from control embryos; (lane 6) stage-10 ectoderm from RAtreated embryos conjugated with mesoderm from RA-treated donors; (lane 7) stage-11.5 dorsal ectoderm from control embryos; (lane 8) stage-11.5 dorsal ectoderm from RA-treated embryos; (lane 9) stage-11.5 dorsal ectoderm and underlying mesoderm from control embryos; (lane 10) stage-11.5 dorsal ectoderm and underlying mesoderm from RA-treated embryos. 
differential response of these anterior-specific genes to RA applied before or after ectoderm had been exposed to inducing mesoderm (Sive et al. 1990) suggested that RA could act to perturb the ectodermal response both prior to and subsequent to induction. The dearth of early, eyespecific markers prevented us from examining whether RA-treated dorsal mesoderm was deficient in eye induction in vitro, as in vivo transplantation assays would suggest.

In summary, these experiments supported data from in vivo transplantation assays and showed that, in vitro, dorsal mesoderm from RA-treated animals was capable of inducing, in control ectoderm, the expression of anterior-specific genes that would have remained silent in RA-treated whole embryos. Ectoderm from RA-treated embryos was not capable of responding normally to induction by dorsal mesoderm.

\section{$R A$ decreases the expression of lateral and ventral mesodermal marker genes}

The reduced amount of anterodorsal mesoderm in RAtreated embryos, indicated by alteration of Xhox.lab RNA distribution and by induction assays, suggested that a compensatory increase in lateral and ventral mesoderm may have been effected by RA. Such compensation is observed in embryos ventralized by treatment with UV light (Cooke and Smith 1987; see below).

Mesodermal fates were monitored directly by changes in specific gene expression. Markers were employed that detected lateral mesoderm (skeletal muscle) and ventral mesoderm (blood). Initially, whole embryos were incubated in RA from blastula to late gastrula stages and were then harvested for RNA analysis at neurula (stage 16; Nieuwkoop and Faber 1956), tail-bud (stage 21), or prehatching (stage 30) stage, in parallel with control embryos of the same stages. The results of this analysis are shown in Figure 6.

Two markers of skeletal muscle declined three- to fourfold after RA application. These were cardiac $(\alpha)$ actin, which is predominantly expressed in skeletal muscle before swimming stages (Mohun et al. 1984), and MyoD, a gene that regulates myogenesis (Davis et al. 1987; Hopwood et al. 1989|. The decline in somitic gene expression was mirrored by a decrease in the number and size of somites in RA-treated embryos (not shown). Additionally, the decrease in muscle-specific gene expression was also seen in isolated mid-gastrula dorsolateral mesoderm exposed to RA in culture (H.L. Sive, unpubl.).

As a marker of ventral mesoderm, the levels of $\alpha$-globin RNA were monitored. In both neurula and tailbud stages, this RNA was expressed at similar low levels in control and RA-treated animals (lanes 1-4). However, by hatching stages, although control animals had increased globin RNA levels $>10$-fold over tail-bud levels, RA-treated embryos expressed globin RNA at only low levels (lanes 5 and 6). This failure to increase globin RNA concentration was mirrored by a precipitous decline in visible red blood in RA-treated animals relative to controls (not shown). Globin RNA levels declined in a time-

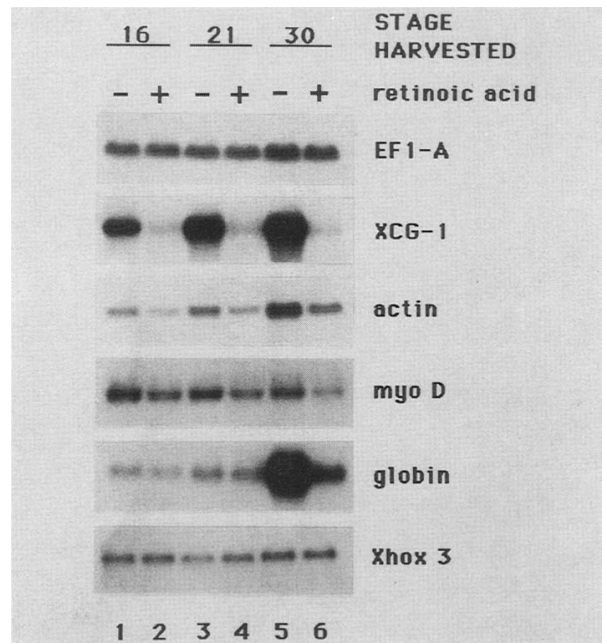

Figure 6. Analysis of mesodermal gene expression after RA treatment. Embryos were treated with $1 \mu \mathrm{M}$ RA for $4 \mathrm{hr}$ from stage 9 until about stage 11 and then later harvested for RNA analysis at neurula (stage 16), tail-bud (stage 21), or prehatching (stage 30) stage. Ten micrograms of nucleic acid was loaded per lane. Probes: (EF-1 $\alpha$ and XCG-1) Controls for RNA loading and the efficacy of RA treatment, respectively (see legend to Fig. 1), (actin) cardiac actin, at these stages, essentially only a marker of skeletal muscle differentiation (Mohun et al. 1984); (MyoD) a muscle regulatory gene (Hopwood et al. 1989); (globin) $\alpha$-globin (Widmer et al. 1983); (Xhox 3) a marker of $\mathrm{A} / \mathrm{P}$ positional value (Ruiz i Altaba and Melton 1989b). Note that the concentration of this RNA did not change at any time of development assayed (see Fig. 3B). Exposure times for MyoD and Xhox 3 were 3 days; for cardiac actin and $\alpha$-globin, 2 days; for XCG-1, 1 day; and for EF- $1 \alpha, 12$ hr. (Lanes 1,3,5) RNA from control embryos, harvested at stages 16,21 , or 30 , respectively; (lanes $2,4,6$ ) RNA from RA-treated embryos, harvested at stages 16,21 , and 30 , respectively.

dependent way to increasing exposure to $10^{-6} \mathrm{M}$ RA /not shown).

In summary, this analysis indicated that with the decline in $\mathrm{A} / \mathrm{P}$ mesoderm, no compensatory increase in lateral or ventral mesodermal differentiation was seen. Rather, expression of lateral mesodermal (muscle) and ventral mesodermal (blood) genes declined in RA-treated embryos. These results also indicated that while UVventralized embryos are superficially similar to RAtreated animals (see Scharf and Gerhart 1983), the molecular details of the phenotypes are quite different.

\section{Discussion}

In this report we have shown that in addition to altering the ectodermal response to induction (Durston et al. 1989; Sive et al. 1990), RA altered the determination of mesodermal lineages and decreased the anterior-inducing ability of the dorsal mesoderm. Our data show that RA grossly altered the expression of putative regulatory genes, and provide insight into the molecular mediators by which RA may perturb anterior patterning along the primary body axis in Xenopus. 
Xhox.lab genes are responsive to $R A$ in both ectoderm and mesoderm

We isolated two homeo-domain-containing genes, Xhox.lab1 and Xhox.1ab2, that are members of the labial gene family (see Fig. 1C), which includes genes from Drosophila (Mlodzik et al. 1988), mouse (LaRosa and Gudas 1988; Frohman et al. 1990), and chicken (Sundin et al. 1990). The expression of the Xenopus genes was quite similar to that of the chicken and mouse homologs, all of which are expressed in more posterior regions, in both ectoderm and mesoderm during early (gastrula and neural plate) stages.

RA induced the Xhox.lab genes $>10$-fold in dorsal ectoderm and mesoderm during gastrulation, when the embryo is most sensitive to RA-mediated axial perturbation. These genes were predominantly expressed in the posterior ectoderm and mesoderm of untreated embryos, but their expression spread to more anterior regions upon RA application. Additionally, Xhox.lab2 RNA, which was normally expressed in middle regions of neurula stages, was induced in more posterior regions upon RA treatment. The chicken labial homolog, Ghox.lab, is also induced in more anterior regions after RA application to gastrulating embryos (G. Eichele, pers. comm.).

These results make several important points. First, the $X$ hox.lab genes may play some role in normal axial patterning. Although it is not known whether endogenous RA induces expression of these genes during normal embryogenesis, a recent report indicates that the RA $\gamma$ receptor is localized in the posterior of gastrula and neurula Xenopus embryos (Ellinger-Ziegelbauer and Dreyer 1991), demonstrating an interesting correlation between the presence of Xhox.lab transcripts and one component of the RA-response system. We propose that if RA has a function during normal axial patterning, it may be bipartite to effect an activation of posteriorspecific gene expression and a concomitant repression of anterior-specific genes in the posterior of the embryo. In this scheme Xhox.lab proteins may act either as transcriptional activators or repressors on downstream target genes.

Second, the response of Xhox.lab genes to RA demonstrated unequivocally that mesodermal, as well as ectodermal, determination was altered by RA. Our data suggest that misexpression of these genes may be part of the mechanism by which axial perturbation in response to RA is mediated. To some extent, this can be tested by asking whether overexpressing these genes in untreated embryos phenocopies the RA response.

Many homeo-domain genes are RA responsive in human tissue culture systems, and the concentration of RA required for maximal stimulation of each gene increases from $3^{\prime}$ to $5^{\prime}$ within several homeo-domain gene clusters (corresponding in vivo to an anterior-to-posterior expression pattern, respectively) (Simeone et al. 1990; Stornaioulo et al. 1990). Although these observations have not yet been extended to whole animals, they suggest that a large cohort of genes may be regulated by different
RA concentrations in vivo and perhaps are responsible for several steps in axial patterning.

\section{$R A$-treated embryos contain a reduced amount of anterior-inducing mesoderm}

A series of induction assays was performed to address whether the alteration in dorsal mesodermal patterning demonstrated by Xhox.lab expression in response to RA also reflected a change in inducing ability of the dorsal mesoderm. Transplantation of organizer /dorsal mesoderm) from normal or RA-treated donors to host gastrulae and in vitro induction assays allowed two conclusions to be made.

First, RA-treated embryos, which developed without anterior structures, including eyes and a cement gland, contained less anterior-inducing dorsal mesoderm than did controls. This was evident in transplantation assays, where dorsal mesoderm from either control or RAtreated early gastrulae was transplanted into UV-irradiated host embryos (Scharf and Gerhart 1983). Although both control and RA-treated mesoderm were able to restore dorsal axial patterning to these otherwise ventralized, anaxial embryos, RA-treated tissue lacked the ability to fully restore anterior development. In particular, RA-treated mesoderm never induced eye formation in this assay, whereas control mesoderm was capable of doing so in a high percentage of transplants (Table 1).

Ruiz i Altaba and Jessell (1991) and Cho et al. (1991) have also recently assayed the effects of RA on the inducing ability of dorsal mesoderm. Our results are in agreement with theirs; they also observed a decline in the anterior-inducing ability of RA-treated dorsal mesoderm. However, the investigators mentioned above were able to observe an effect of RA when dorsal mesoderm was transplanted into normal host embryos, whereas we saw differences between the inducing ability of control and RA-treated mesoderm when these tissues were transplanted into UV-irradiated, but not normal, embryos. The varying responses of the assays in our study may result from different details of the transplantation techniques. We suggest that, in our hands, the organizer in normal embryos may have rescued the implanted RAtreated organizer (Stewart and Gerhart 1990), whereas UV-irradiated embryos, which lack a normal organizer, may have been unable to effect rescue.

The second conclusion is that RA-treated animals contained some anterior-inducing mesoderm, as evidenced by the ability of this tissue to induce a cement gland both in transplantation assays and in vitro induction assays. Because this organ was completely absent from RAtreated donors, such anterodorsal-inducing ability must have been prevented from realizing its potential in whole animals. Eye induction corresponds to a more extreme anterior positional value than cement gland, on the basis of the greater sensitivity of eyes over cement gland to perturbation by RA or UV treatment (Scharf and Gerhart 1983; Sive et al. 1990). Our data therefore indicate that only the most anterior-inducing ability was lost with RA application. 


\section{RA-treated ectoderm does not respond normally to induction}

The discovery of cryptic anterodorsal-inducing ability in RA-treated embryos indicated that this activity was prevented from acting by a lesion in the responding dorsal ectoderm. Additional experiments assayed the response of donor ectoderm to conjugation with dorsal mesoderm. In vitro induction assays showed that ectoderm removed from RA-treated donors was not able to respond normally to mesodermal induction and was not induced to express the full spectrum of anterior-specific genes assayed. Furthermore, in transplantation assays, embryos that had been exposed to a pulse of RA did not form head structures with either control or RA-treated head organizer as donor (not shown). These data supported those presented previously (Durston et al. 1989; Sive et al. 1990) and indicated that ectoderm was a target for RA both during and subsequent to its induction.

\section{$R A$ causes only a partial $A / P$ transformation}

Although our data further indicated that RA transformed anterior positional values to more posterior ones (Durston et al. 1989; Sive et al. 1990), the transformation was not a simple one and was only partial. In particular, not all posterior genes were induced anteriorly by RA. For example, RA did not alter the levels or distribution of the homeo-domain gene Xhox 3, a gene involved in posterior patterning of the dorsal mesoderm (Ruiz i Altaba and Melton 1989a,b,c). Ruiz i Altaba and Jessell (1991) have obtained a similar result independently. These results indicate that posterior patterning requires more than one factor, which may include RA, but is not solely caused by this substance.

That RA was not sufficient to cause posterior patterning was also supported by transplantation of organizer (dorsal mesoderm) into host embryos. Although our data showed that RA-treated organizers were somewhat deficient in anterior-inducing ability, no concomitant increase in induced posterior structures was observed in these assays (Table 1). Similar results have been obtained recently by Ruiz i Altaba and Jessell (1991) and Cho et al. (1991).

The foregoing conclusions were further supported by the inability of RA to reverse the anteriorizing effects of lithium, which are brought about by hyperinduction of (antero)dorsal mesoderm (Kao and Elinson 1988). Although RA was able to prevent head formation in lithium-treated embryos, it was not able to restore posterior development and to restore a tail (data not shown).

It was of interest that Xhox.lab2 RNA became expressed in regions more posterior than those in which it is normally found, because embryos develop without a tail at high RA concentrations (Sive et al. 1990). Formation of the tail occurs subsequent to gastrulation (Nieuwkoop et al. 1985) and may represent a second target for RA that is perhaps mediated by Xhox.lab2 expression.

Clearly, the overexpression of certain homeo-domain genes can be sufficient to effect a morphologically obvi- ous A/P transformation (Kessel et al. 1990). Our data indicate, however, that complete $\mathrm{A} / \mathrm{P}$ patterning must require a composite of events and expression of different genes that RA alone is not able to precipitate.

\section{$R A$ does not effect a general dorsoventral transformation}

The decrease in anterodorsal mesoderm effected by RA and its partial transformation to more posterior values was not accompanied by an increase in lateral (muscle) and ventral (blood) mesodermal tissues. Such compensatory changes are seen in embryos ventralized by a pulse of UV light applied soon after fertilization (Scharf and Gerhart 1983; Cooke and Smith 1987). Rather, RA caused a decrease in both the size and number of somites (not shown) and in the expression of muscle-specific genes. Ruiz i Altaba and Jessell (1991) have examined the effect of RA on mesodermal patterning in Xenopus and have also observed a suppression of muscle differentiation in the presence of RA. A depression of somite development by RA also has been reported in hamster embryos (Marin-Padilla 1966).

Additionally, in RA-treated embryos, both the visible amount of red blood cell differentiation (not shown) and levels of $\alpha$-globin RNA were dramatically lower than those of controls in hatching-stage embryos. Prior to this stage, no difference in a basal $\alpha$-globin RNA level was seen between control and RA-treated animals. These results were of interest as they implied at least a two-step process by which maximal globin gene expression was elicited. An early RA-insensitive step was required for the initial onset of expression, whereas a later RA-sensitive step appeared to reinforce initial induction. Ventral mesoderm apparently requires an interaction with vegetal endoderm for induction of blood (see Nieuwkoop et al. 1985); perturbation of either of these tissues by RA could account for the absence of the reinforcement step.

Ruiz i Altaba and Jessell (1991) concluded that the amount of ventral mesoderm-scored morphologically as mesenchyme-increased with RA-mediated axial truncation. Through the use of a molecular marker (globin) for ventral mesoderm, our data did not support this conclusion. Although the response of different ventral mesodermal tissues to RA may differ, our data show unequivocally that RA did not effect a general increase in the amount of ventral mesoderm.

\section{$R A$ may alter axial patterning by a dual ectodermal and mesodermal perturbation}

The data presented here strongly suggested that the lesion directing anterior truncation in animals exposed to RA lay both in a deficit of anterior-inducing mesoderm and in the inability of the ectoderm to respond normally to the inducing signal. One important question that remains unanswered is whether RA acts through the same molecular route at all times during embryogenesis. For example, cement gland development can be prevented by a pulse of RA applied either before or after induction of 
this organ (Sive at al. 1990). As is shown in this study, induction of one anterior-specific gene (XA-1) (see Hemmati-Brivanlou et al. 1990) was insensitive to RA treatment of the ectoderm prior to induction but was sensitive after induction (Sive et al. 1990). It is possible that early during development RA perturbs axial patterning chiefly by changing the inducing ability of mesoderm, whereas later, alteration ectodermal determination is the chief pathway affected. We do not currently know whether Xhox.lab RNAs are differentially inducible in ectoderm or mesoderm when RA is applied at different times of development. Further analysis of the response of $X$ hox.lab genes to RA and of the response of embryos to misexpression of these genes might allow some insight into the role of RA in patterning the primary body axis.

\section{Materials and methods}

Growth and culture of embryos

Embryos were obtained from adult $X$. laevis, as described in Sive et al. (1989).

\section{Dissections, transplants, and in vitro induction experiments}

For organizer dissections, a region including the dorsal blastopore lip and extending $\sim 30^{\circ}$ above it was removed from stage10.25 embryos (Nieuwkoop and Faber 1956). Both superficial and deep mesoderm and endoderm were included in the explant. Each explant was inserted into the blastocoel through a slit made in the apex of the animal hemisphere of UV-irradiated hosts.

Dissections of stage-10 ectoderm and stage- 11.5 dorsal mesoderm were performed as described in Sive et al. (1990). For the explants shown in Figure 2 (lanes 7-10), explanted tissue extended from the anterior-most extent of dorsal mesoendoderm invagination to (but not including) the blastopore. In some cases, induced dorsal ectoderm was peeled from the mesoendoderm and cultured separately.

\section{$R A$ and $U V$-light treatments}

RA stocks and treatment were as described in Sive et al. (1990) and the text.

UV irradiation was performed according to Scharf and Gerhart (1983). Embryos were placed on a $260-\mathrm{nm}$ radiation source (UVGL-25 lamp) and irradiated for 60-90 sec through Saran wrap. Irradiation was performed at $\sim 0.5$ of the interval between fertilization and first cleavage (90 $\mathrm{min})$.

\section{Plasmids and inserts}

Isolation of inserts from pXCG-1, pXAG-1, pXA-1, E13, and XIF3 were as described in Sive et al. (1990). For cardiac-actin assays, the SmaI insert was obtained from the M2 cDNA clone described by Mohun et al. (1984). A BamHI-EcoRI fragment of pSP73-M24/3 of the MyoD cDNA clone described in Hopwood et al. (1989) was used. A PstI fragment of the cDNA clone pGEM $\alpha$ Tla was employed as an $\alpha$-globin probe (Widmer et al. 1981; M. Bolce and R. Harland, unpubl.). For Xhox3 assays, an EcoRI insert of pCX3 was employed (Ruiz i Altaba and Melton 1989 a). For EF- $1 \alpha$ detection, the EcoRI insert of pXefl was used (Krieg et al. 1989).

\section{Northern analysis and probe preparation}

Northern analysis and total nucleic acid preparation from explants were as described in Sive et al. (1990). Whole embryo nucleic acid was prepared by proteinase $\mathrm{K}$ digestion and phenol extraction as described in Condie and Harland (1987).

Probes were prepared either by random priming of inserts (Boeringher Mannheim kit) or by asymmetric amplification of inserts using the polymerase chain reaction (PCR). For the latter, $0.1-0.2 \mu \mathrm{g}$ of one or more primers that hybridized to the sense DNA strand (17- to 20-mer) was used in conjunction with standard PCR buffer $(50 \mathrm{mM} \mathrm{KCl}, 10 \mathrm{mM}$ Tris- $\mathrm{HCl} / \mathrm{pH} 8.4$ at room temperature), $1.5 \mathrm{mM} \mathrm{MgCl}_{2}, 100 \mu \mathrm{g} / \mathrm{ml}$ gelatin) and 0.5 units of Taq polymerase (Stratagene) per 10- $\mu \mathrm{l}$ reaction. Deoxynucleotide triphosphates were used at $10-25 \mu \mathrm{M}$ per reaction, which enabled the radiolabeled and cold nucleotide concentrations to be similar, a criterion that was most important for maximal probe length $(\sim 1-2 \mathrm{~kb}$ after 35 cycles).

\section{Fixation}

For analysis of organizer transplants, embryos were fixed as described in Sive et al. (1990).

\section{Isolation of Xhox.lab cDNAs}

A stage-11 cDNA library (made in $\lambda Z$ Zap, Stratagene; a generous gift of Richard Harland, Berkeley/ was screened at low stringency with the Ghox.lab homeo domain (Sundin et al. 1990), employing Church-Gilbert hybridization conditions at $50^{\circ} \mathrm{C}$ (Church and Gilbert 1984). Positive clones were excised from the phage as plasmids, according to the manufacturer, and sequenced by the dideoxy method, with a kit from U.S. Biochemical.

\section{Acknowledgments}

Thanks go to Eddie de Robertis, Gregor Eichele, John Gurdon, Richard Harland, Paul Krieg, Doug Melton, Jim Roberts, Ariel Ruiz i Altaba, Colin Sharpe, and Olof Sundin for plasmids. H.L.S. is extremely grateful to Hal Weintraub for space, support, interest, and criticism. Many thanks go to Andrew Lassar for suggestions, comments, and encouragement and to members of the Weintraub lab for discussion of the manuscript. This work was supported by a National Institutes of Health Molecular Training Program in Cancer Research grant.

The publication costs of this article were defrayed in part by payment of page charges. This article must therefore be hereby marked "advertisement" in accordance with 18 USC section 1734 solely to indicate this fact.

Sequence data have been submitted to EMBL/GenBank.

\section{References}

Berridge, M.J., C.P. Downes, and M.R. Hanly. 1989. Neural and developmental actions of lithium: A unifying hypothesis. Cell 59: 411-419.

Cho, K.W.Y. and E.M. de Robertis. 1990. Differential activation of Xenopus homeo box genes by mesoderm-inducing growth factors and retinoic acid. Genes \& Dev. 4: 1910-1916.

Cho, K.W.Y., E.A. Morita, C.V.E. Wright, and E.M. de Robertis. 1991. Overexpression of a homeodomain protein confers axis-forming activity to uncommitted Xenopus embryonic cells. Cell 65: 55-64.

Church G.M. and W. Gilbert. 1984. Genomic sequencing. Proc. Natl. Acad. Sci. 81: 1991-1995.

Condie, B.G. and R.M. Harland. 1987. Posterior expression of a homeobox gene in early Xenopus embryos. Development 101: 93-105. 
Cooke, J. and J.C. Smith. 1987. The mid-blastula cell cycle transition and the character of mesoderm in UV-induced nonaxial Xenopus development. Development 99: 197-210.

Dale, J. and J.M.W. Slack. 1987. Regional specification within the mesoderm of early embryos of Xenopus laevis. Development 100: 279-295.

Davis, R.L, H. Weintraub, and A.B. Lassar. 1987. Expression of a single transfected cDNA converts fibroblasts to myoblasts. Cell 60: 733-746.

Durston, A.J., J.P.M. Timmermans, W.J. Hage, H.F.J. Hendriks, N.J. de Vries, M. Heideveld, and P.D. Nieuwkoop. 1989. Retinoic acid causes an anteroposterior transformation in the developing central nervous system. Nature 340: 140-144.

Eichele, G. 1989. Retinoids and vertebrate limb pattern formation. Trends Genet. 5: 246-251.

Ellinger-Ziegelbauer, H. and C. Dreyer. 1991. A retinoic acid receptor expressed in the early development of Xenopus laevis. Genes \& Dev. 5: 94-104.

Frohman, M., M. Boyle, and G.R. Martin. 1990. Isolation of the mouse Hox 2.9 gene: Analysis of embryonic expression suggests that positional information along the anterior-posterior axis is specified by mesoderm. Development 110: 589 607.

Gerhart, J. and R. Keller. 1986. Region-specific cell activities in Amphibian gastrulation. Annu. Rev. Cell Biol. 2: 201-229.

Gerhart, J.C., M. Danilchick, T. Doniach, S. Roberts, B. Rowning, and R. Stewart. 1989. Cortical rotation of the Xenopus egg: Consequences for the anteroposterior pattern of embryonic development. Development 107: 37-52.

Hemmati-Brivanlou, A., D. Frank, M.E. Bolce, B.D. Brown, H.L. Sive, and R.M. Harland. 1990. Localization of specific mRNAs in Xenopus by whole mount in situ hybridization. Development 110: 325-330.

Hopwood, N.D., A. Pluck, and J.B Gurdon. 1989. MyoD expression in the forming so mites is an early response to mesoderm induction in Xenopus embryos. EMBO. I. 8: 34093417.

Kao, K.R. and R.P. Elinson. 1988. The entire mesodermal mantle behaves as Spemann's organizer in dorsoanterior enhanced Xenopus laevis embryos. Dev. Biol. 127: 64-77.

Keller, R.E. 1976. Vital dye mapping of the gastrula and neurula of Xenopus laevis. 1. Prospective areas and morphogenetic movements in the deep region. Dev. Biol. 51:118-137.

Kessel, M., R. Balling, and P. Gruss. 1990. Variations of cervical vertebrae after expression of a Hoxl.1 transgene in mice. Cell 61: 301-308.

Kobel, H.R. and L. DuPasquier. 1986. Genetics of polyploid Xenopus. Trends Genet. 2: 310-315.

Krieg, P.A., S.M.Varnum, W.M. Wormington, and D.A. Melton. 1989. The mRNA encoding elongation factor 1 alpha (EFlalpha) is a major transcript at the mid-blastula transition in Xenopus. Dev. Biol. 133: 93-100.

LaRosa, G.J. and L.J. Gudas. 1988. Early retinoic acid-induced F9 teratocarcinoma stem cell gene ERA-1: Alternate splicing creates transcripts for a homeobox-containing protein and one lacking the homeobox. Mol. Cell. Biol. 8: 3906-3917.

Marin-Padilla, M. 1966. Mesodermal alterations induced by hypervitaminosis A. J. Embryol. Exp. Morphol. 15: 261-269.

Mlodzik, M., A. Fjose, and W. Gehring. 1988. Molecular structure and spatial expression of a homeo box gene from the labial region of the Antennapedia-complex. EMBO $J$. 7: 2569-2578.

Mohun, T.J, S. Brennan, N. Dathan, S. Fairman, and J.B. Gurdon. 1984. Cell type-specific activation of actin genes in the early amphibian embryo. Nature 311: 716-721.

Nieuwkoop, P.D. and J. Faber. 1956. Normal table of Xenopus laevis (Daudin). North-Holland Publishing Company, Amsterdam.

Nieuwkoop, P.D., A.G. Johnen, and B. Albers. 1985. The epigenetic nature of early chordate development. Cambridge University Press, Cambridge.

Ruiz i Altaba, A. and T. Jessell. 1991. Retinoic acid modifies mesodermal patterning in early Xenopus embryos. Genes \& Dev. 5: 175-188.

Ruiz i Altaba, A. and D.A. Melton. 1989a. Interaction between peptide growth factors and homeo box genes in the establishment of antero-posterior polarity in frog embryos. $\mathrm{Na}$ ture 341: 33-38.

- 1989b. Bimodal and graded expression of the Xenopus homeo box gene Xhox 3 during embryonic development. Development 106: 173-183.

- 1989c. Involvement of the Xenopus homeo box gene Xhox 3 in pattern formation along the anteroposterior axis. Cell 57: 317-326.

Scharf, S.R. and J.C. Gerhart. 1983. Axis determination in eggs of Xenopus laevis: A critical period before first cleavage, identified by the common effects of cold, pressure and ultraviolet irradiation. Dev. Biol. 99: 75-87.

Schneuwly, S., A. Kuroiwa, P. Baumgartner, and W.J. Gehring. 1986. Structural organization and sequence of the homeotic gene Antennapedia of Drosophila melanogaster. EMBO J. 5: 733-739.

Sharpe, C.R., A. Pluck, and J.B. Gurdon. 1989. XIF3, a Xenopus peripherin gene, requires an inductive signal for enhanced expression in anterior neural tissue. Development 107: 701714

Simeone, A., D. Acampora, L. Arcioni, P.W. Andrews, E. Boncinelli, and F. Mavillo. 1990. Sequential activation of Hox2 homeo box genes by retinoic acid in human embryonal carcinoma cells. Nature 346: 763-766.

Sive, H.L., K. Hattori, and H. Weintraub. 1989. Progressive determination during formation of the anteroposterior axis in Xenopus laevis. Cell 58: 171-180.

Sive, H.L., B.W. Draper, R.M. Harland, and H. Weintraub. 1990. Identification of a retinoic acid-sensitive period during primary axis formation in Xenopus laevis. Genes \& Dev. 4: 932-942.

Smith, J.C. 1989. Mesoderm induction and mesoderm-inducing factors in early amphibian development. Development 105: 665-677.

Spemann, H. 1938. Embryonic development and induction. Yale University Press, New Haven.

Stewart, R. and J.C. Gerhart. 1990. The anterior extent of dorsal development of the Xenopus embryonic axis depends on the quantity of organizer in the late blastula. Development 109: 363-372.

Stornaiuolo, A, D. Acampora, M. Pannese, M. D'Esposito, F. Morelli, E. Migliaccio, M. Rambaldi, A. Faiella, V. Nigro, A. Simeone, and E. Boncinelli. 1990. Human Hox genes are differentially activated by retinoic acid in embryonal carcinoma cells according to their position within the four loci. Cell Differ. Dev. 31: 119-127.

Sundin, O.H., H.G. Busse, M.B. Rogers, L.J. Gudas, and G. Eichele. 1990. Region-specific expression in early chick and mouse embryos of Ghox.lab and Hoxl.6, vertebrate homeo box-containing genes related to Drosophila labial. Development 108: 47-58.

Widmer, H.J., A. Andres, J. Niessing, H.A. Hosbach, and R. Weber. 1981. Comparative analysis of cloned larval and adult globin cDNA sequences of Xenopus laevis. Dev. Biol. 88: $325-332$. 


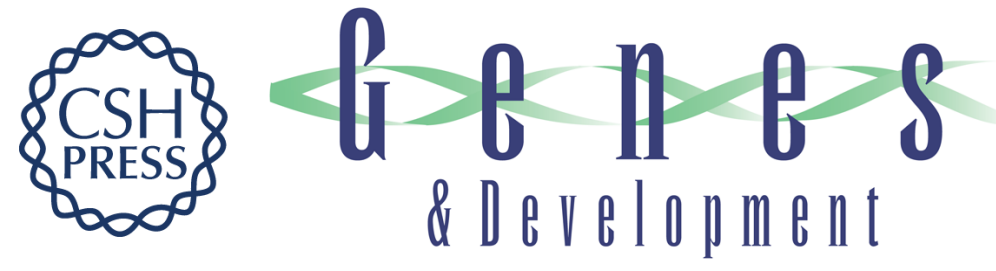

\section{Retinoic acid perturbs the expression of Xhox.lab genes and alters mesodermal determination in Xenopus laevis.}

$\mathrm{H} L$ Sive and P F Cheng

Genes Dev. 1991, 5:

Access the most recent version at doi:10.1101/gad.5.8.1321

References This article cites 40 articles, 17 of which can be accessed free at: http://genesdev.cshlp.org/content/5/8/1321.full.html\#ref-list-1

License

Email Alerting

Service

Receive free email alerts when new articles cite this article - sign up in the box at the top right corner of the article or click here.

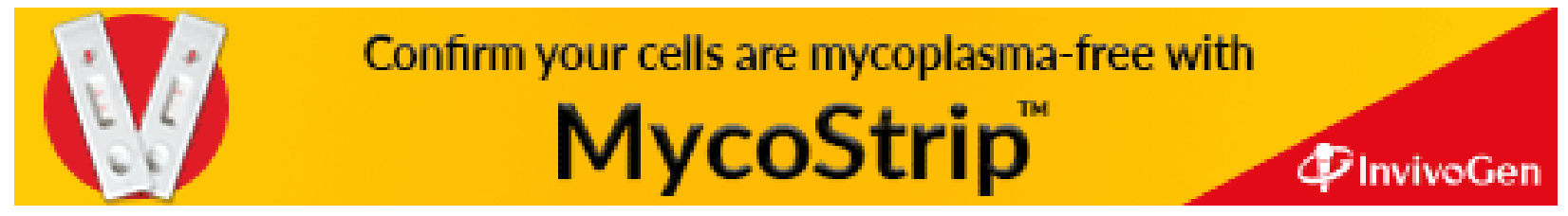

